\title{
Can Piezoelectric Tiles be a solution for a Sustainable Classroom? A case study from Sreenidhi International School
}

Paras Joshi

Parasjoshi122@gmail.com, +919515990675

Chirec International School, Hyderabad, India

https://orcid.org/0000-0002-9113-1529

\begin{abstract}
With the depletion of natural resources, it has become a topic of great concern to address the unsustainable way of life. In this study, we investigate the use of piezoelectric material - to generate electricity in schools. The use of these piezoelectric materials in floor tiles could enable us to generate energy from the footsteps of the children in school. The goal is to be able to power lights and fans in classrooms and reduce the consumption of conventional electricity produced through the combustion of coal and other natural resources. The primary method of research is to develop a prototype with different choices of material and configurations of piezoelectric transducers to maximize power generation in a typical school setting. The results showed that the energy generated from one step needs to be improved by a factor of 100 for a typical classroom to generate enough power for a light and a fan. The research found that current technology, although promising, is incapable of producing enough power via piezoelectric tiles in a school setting.
\end{abstract}

Keywords: piezoelectric tiles, school, sustainability, prototype

\section{Introduction}

With the depletion of natural resources, it has become a topic of great concern to address the unsustainable way of life. Almost 8 billion tons of highly polluting coal is burnt every year to sustain the generation of electricity.

To take Sreenidhi International School - located in Hyderabad, Telangana India - a step closer towards sustainability, the use of piezoelectric material - to generate electricity- is an idea worth considering. The use of these piezoelectric materials in floor tiles could enable us to generate energy from the footsteps of the children in school. The goal of this idea is to be able to power lights and fans in classrooms and reduce the consumption of conventional electricity.

In this research work, we study the effectiveness of this idea and provide conclusive recommendations on its application in the specific school environment. 


\section{About piezoelectricity[16]}

Piezoelectric materials are crystals that range from simple salts to quartz crystals. Piezoelectric materials convert some of the work done in deforming it into electrical energy. The proposed idea exploits this property.

Piezoelectric materials have a crystal lattice but naturally, they have some defects in their lattice structure. The interstitial vacancy is a defect where the crystal lattice is missing an atom or molecule in its crystal structure, resulting in gaps in the structure. Thus, under the application of stress, a polarity[9] is generated in the crystal, resulting in the development of potential differences across the crystal.

The main purpose of using piezoelectric material in tiles is to convert the mechanical energy generated by walking, which is otherwise wasted, into electrical energy. The application of these types of crystals in the designing of the tiles is appropriate since they give rise to polarity when deformed. The steps taken on the tile would generate the force causing deformation in the crystal and thus producing energy.

\section{School setting and data}

Sreenidhi international school has a total of around 1500 students, out of which $48 \%$ of them are secondary school students. The school classrooms are concentrated into two buildings: one for primary and one for secondary students. The secondary school students have different classes in their respective rooms and must walk to different classes. All classes are connected by corridors and are widely used by students of secondary school. On average a student takes three thousand steps throughout the day, in school. This reading does not account for the steps taken while performing any physical activity. The number of steps reported is through the corridors, transferring from one class to another. A potential spot for the application of the piezoelectric material.

The school also has a common dining area where primary school and secondary school students come to have lunch, at different times. The dining area has a designated path or line to collect food from the serving station. This results in a high concentration of students in one restricted area potentially making a good spot for the application of piezoelectric material.

\section{Basic terminology and concepts}


Piezoelectric material has certain characteristics that dictate its ability to store energy. The amount of energy stored in a piezoelectric material depends on many factors like dimensions, type of crystal, and other intrinsic properties of the crystal.

Five piezoelectric materials that could potentially make this idea feasible are Quartz crystal, Lithium Niobate, PVDF, PZT-NCE55, and Rochelle salt crystals. The choice of these materials has been made based on their ability to store energy, i.e. is capacitance; on their ability to generate maximum voltage along a geometrical axis, and on their ability to withstand a certain type of strain.

To understand the reasoning behind the selected choice of material it is important to understand and get familiarized with some of the technical terms used in the consideration.

\section{Poling[9]}
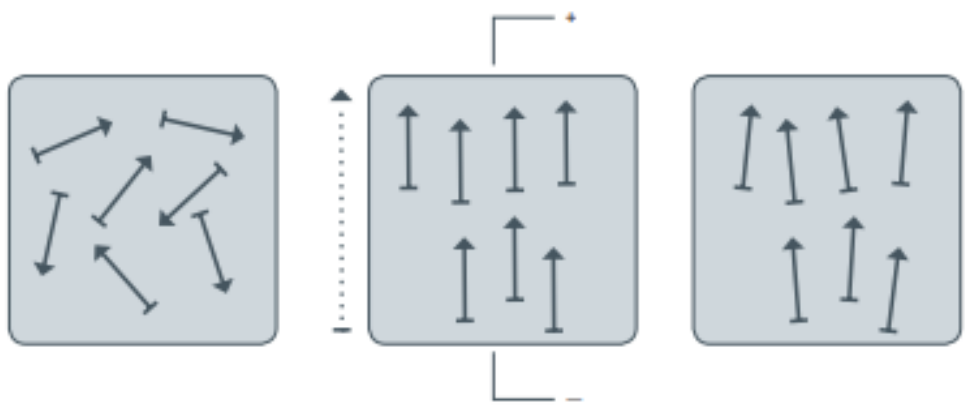

Piezoelectric material is made up of smaller electric dipoles which are in a random orientation resulting in a net-zero dipole moment. However, if an electric field is applied across the piezoelectric material the dipoles tend to align and result in a net dipole even after the removal of the electric field. 
Piezoelectric constitutive equations[9]:

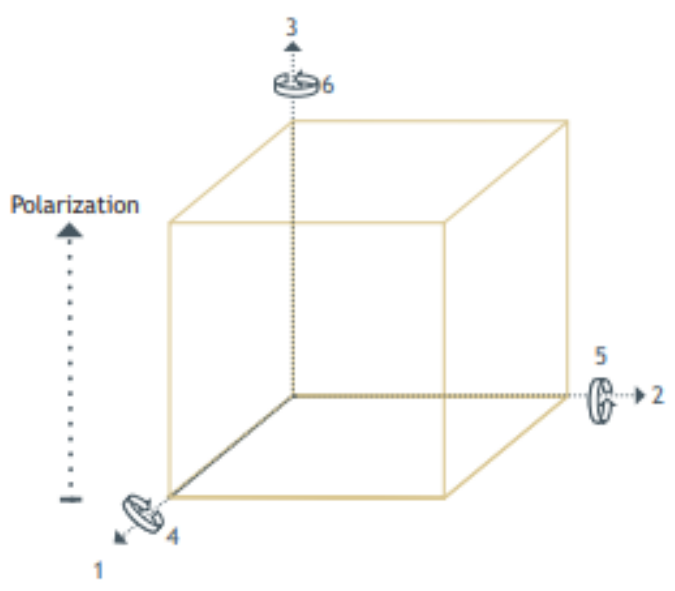

The piezoelectric effect is pronounced in different directions along the crystal. The reference axis, axis 3, is always taken along the axis of poling. Axis 1 and 2 in such a way that they form a coordinate system with axis 3 . The shearing or twisting movement along the axes is referred to as $4,5,6$ as shown in the figure.

Relative dielectric constant[17,9]:

Permittivity is the ability to store electrical energy in an electric field in that medium. The ratio of the permittivity of the material with that of permittivity of free space is known as the relative dielectric constant. It describes how many times greater is the permittivity of the material than the permittivity of free space. It is referred to as $\mathrm{K}^{\top}$. The notation $\mathrm{K}_{3}{ }^{\top}$ means that the electrodes are perpendicular to axis 3 and $T$ refers to saying the stress on the material is constant.

Piezoelectric charge constants[14,9]

It is the polarization generated per unit mechanical stress applied to the piezoelectric material. It is denoted as $\mathbf{d}_{\mathfrak{I} J}$ where I refers to the axis to which the electrodes are perpendicular, and $\mathrm{J}$ refers to the axis along which the mechanical strain is applied.

Piezoelectric voltage constants[9]

It is the field developed per unit mechanical stress in the piezoelectric material. It is denoted as $\mathbf{g}_{\mathrm{IJ}}$, where I refers to the axis to which the electrodes are perpendicular, and $\mathrm{J}$ represents the axis along which the mechanical strain is applied.

\section{Electromechanical coupling[15,9]:}

It is the effectiveness with which the piezoelectric material converts mechanical energy to electrical energy. It is denoted as $\mathbf{k}_{\mathbf{I} J}$, where $\mathbf{I}$ is the axis to which the electrodes are perpendicular, and $\mathrm{J}$ is the axis along which the mechanical strain is applied. 
Elastic compliance[9]:

It is the measure of strain produced in the material per unit stress. This gives an idea about the material's strength and elasticity. It is the inverse of young's modulus. It is denoted as $\mathbf{S}_{\mathrm{IJ}} \mathbf{E}$, where $E$ indicates the measure of compliance under closed circuit; I and $\mathrm{j}$ refer to the direction of strain and stress.

\section{Piezoelectric Tile Prototype Design and Tradeoffs}

To investigate how piezoelectric material can be used in tiles and understand its limitations and advantages, a prototype was built to carry out different sets of experiments to collect data that can later be analyzed.

The following experiments help enhance the understanding and practicality of such a product in real-life scenarios. These experiments are aimed at addressing some of the questions that arise during the process of designing and building such a product.

* It should be noted that the experiments were carried out with a prototype design that used piezoelectric transducers to generate electricity. These transducers were the most easily available resource and enough to provide us with data that can enhance our knowledge on the practical application of this product.

\section{Weight vs Voltage}

This experiment focuses on the voltage generated across a piezoelectric transducer on each step taken on the tile, by people of different weights.

\begin{tabular}{|l|l|}
\hline \multicolumn{1}{|c|}{ Weight $(\mathrm{Kg})$} & Output Volts $(\mathrm{V})\left(\right.$ Energy $\left.=1 / 2 \mathrm{C}^{*} \mathrm{~V}^{2}\right)$ \\
\hline 49 & $1.25 \mathrm{~V}$ \\
\hline 79 & $1.62 \mathrm{~V}$ \\
\hline 60 & $1.60 \mathrm{~V}$ \\
\hline 82 & $1.65 \mathrm{~V}$ \\
\hline
\end{tabular}

${ }^{*}$ Capacitance

The number of transducers that can be incorporated in a tile to increase efficiency is an important aspect that needs to be investigated to design the most efficient and cost-effective tile. 
I placed the piezoelectric transducer on a weighing scale and connected it to a voltmeter. The weighing machine showed me the amount of force exerted by me on the tile and voltmeter the voltage for that force. Thus, I saw that to bring about $1.5 \mathrm{v}$ to $2 \mathrm{v}$ we need a force of $11 \mathrm{~kg}-15 \mathrm{~kg}$. Thus only 3 or 4 transducers can be placed in one tile (assuming an average student weighs $60 \mathrm{kgs})$.

\section{Transducers in Parallel vs Series Circuit}

The transducers are connected to a temporary energy storage unit, a capacitor. The transducers can be connected in two ways: in a series connection or a parallel connection.

This experiment is aimed at enhancing our knowledge on what types of connections can maximize efficiency.

\section{Series connections}

\begin{tabular}{|l|l|l|}
\hline Serial number & $\begin{array}{l}\text { Voltage reading of individual } \\
\text { transducer }\end{array}$ & $\begin{array}{l}\text { Voltage reading from series } \\
\text { of 4 transducers. }\end{array}$ \\
\hline 1 & 2.00 & 0.20 \\
\hline 2 & 1.90 & 0.18 \\
\hline 3 & 1.63 & 0.2 \\
\hline 4 & 2.00 & 0.14 \\
\hline
\end{tabular}

Transducers connected in series were designed by connecting the positive of one transducer to the negative of the other until the final transducer was connected to a voltmeter. The voltmeter displayed very low readings, observing a maximum of 0.2 volts after connecting the transducers in series. However, each transducer was able to produce 1.88 volts, on average, under the same conditions.

This observation can be explained by acknowledging the fact that the transducers are individual sources of energy, like batteries. The current flowing from one transducer is used by the adjacent transducers to vibrate at very high frequencies. Each piezoelectric transducer is acting a load in the circuit and powering the adjacent transducer from the voltage generated across itself. The vibrations of the piezoelectric transducer are the cause of generation of a small voltage across 
itself, giving rise to a small current. The voltage reading in the voltmeter shows the voltage across the last piezoelectric transducer, that is generated due to its vibrations.

Data analyzed from this experiment discourages the use of series connections between piezoelectric transducers in the product.

\section{Parallel connections}

There are two ways to connect the transducers in parallel. One way is to connect each transducer individually to a capacitor and then connect the capacitors in parallel using a diode, so that the capacitors don't charge each other. The second is to connect all the transducers in parallel to one capacitor, using a diode and rectifier to direct the flow of current in one direction.

The maximum voltage observed in the voltmeter across each transducer was 2 volts. However, it must be determined which of the two ways of making parallel connections is more effective and efficient.

Transducers Connected to Individual Capacitors and Single Capacitor

\begin{tabular}{|c|c|c|c|c|}
\hline \multicolumn{5}{|c|}{ Individual transducer capacitor arrangement } \\
\hline Number of steps & $\begin{array}{c}\text { Capacitor } 1 \\
\text { (100uF) } \\
\text { (v) }\end{array}$ & $\begin{array}{c}\text { Capacitor } 2 \\
\text { (100uF) } \\
\text { (v) }\end{array}$ & $\begin{array}{c}\text { Capacitor } 3 \\
\text { (100uF) } \\
\text { (v) }\end{array}$ & $\begin{array}{c}\text { Capacitor } 4 \\
\text { (100uF) } \\
\text { (v) }\end{array}$ \\
\hline 30 & 0.24 & 0.23 & 0.21 & 0.40 \\
\hline 60 & 0.47 & 0.39 & 0.40 & 0.71 \\
\hline 100 & 0.86 & 0.56 & 0.63 & 1.20 \\
\hline 130 & 1.10 & 0.68 & 0.72 & 1.45 \\
\hline $\begin{array}{c}\text { Average voltage } \\
\text { in capacitor after } \\
130 \text { steps }\end{array}$ & \multicolumn{4}{|c|}{1 volt } \\
\hline $\begin{array}{l}\text { Average energy } \\
\text { in each capacitor } \\
\text { after } 130 \text { steps }\end{array}$ & \multicolumn{4}{|c|}{50 micro joules } \\
\hline
\end{tabular}




\begin{tabular}{|c|c|}
\hline \multicolumn{2}{|c|}{ All 4 transducers connected in parallel to single Capacitor } \\
\hline Number of steps & Voltage in capacitor (100uF) \\
(v)
\end{tabular}

Comparing the observations of the two experiments we can clearly read a higher average voltage being obtained in the second circuit. Also comparing the amount of energy in a capacitor after 130 steps, we observe that the amount of energy generated in the second circuit is 4 times of that available in the first circuit.

Thus, it can conclusively be deduced that the connections between transducers, in the product, should be made in parallel- connecting each transducer to a separate capacitor first and then taking an output from those capacitors.

\section{CHOICE OF MATERIAL}

The choice of material used in the product is a key aspect to increase efficiency. The best material suited for this product must be identified based on a certain set of criteria. 
The energy generated by a piezoelectric crystal is proportional to the square of the voltage produced across the piezoelectric crystal, while it is only proportional to the first order of the capacitance of the crystal. However, capacitance and voltage are inversely proportional to each other, thus it is ideal to try to maximize voltage as it has a greater effect on the energy produced in the piezoelectric crystal. The effect of increase in energy from increase in voltage is greater than the effect of decrease in energy due to decrease in capacitance.

\section{Force and piezoelectric voltage constant[]]}

The force will act perpendicular to the surface of the tile, thus the surface of the crystal parallel to the surface of the tile will act as electrodes[9]. Thus, the electric field in the piezoelectric crystal will be generated parallel to the direction of force. Thus, we must use crystals that have the maximum voltage constants $\left(\mathbf{g}_{\mathbf{i}}\right)$ in the direction $\mathbf{g}_{\mathbf{3} 3}$.

\section{Dimensions and force}

The surface area and the thickness of each piezoelectric crystal (distance between the charged surfaces of the crystal) are both determining factors in voltage and capacitance. However, the ratio of thickness: surface area is proportional to voltage and inversely proportional to capacitance. But since voltage is the driving factor of energy produced by a single piezoelectric crystal, the objective is to maximize voltage- by decreasing surface area and increasing thickness.

The thickness chosen for the analysis of the different materials is $1 \mathrm{~cm}$. It was observed during the prototype design that anything greater in size was causing difficulty in walking on the tiledue to subtle movement of the surface.

However, to accommodate for the decrease of surface area of the piezoelectric crystal we can place multiple piezoelectric crystals inside a tile. Experiments show that the average weight of a middle and high schooler is around 50-60 kgs, roughly producing 600 newtons of force on each step. Since the force required per piezoelectric crystal, to work at optimum energy efficiency, has to produce a voltage of $75 \%$ of the dielectric strength, the number of piezoelectric crystals that can be placed in a tile is restricted.

\section{Stress experienced by crystal}

The product will undergo a lot of stress as people take steps on it. It is important that the piezoelectric crystal used be able handle the constant stress without breaking. The elastic 
compliance is the measure of strain produced per unit stress, thus a crystal with lower elastic compliance is ideal.

\section{Conversion efficiency}

The efficiency with which a piezoelectric material can convert mechanical energy to electrical energy is the most important property of the material. It is represented by electromechanical[9] coupling factor $\left(\mathrm{K}_{\mathrm{ij}}\right)$ and the higher the value of $\mathrm{K}_{\mathrm{ij}}$ the more ideal the material for the product.

\section{Properties of different materials}

\begin{tabular}{|c|c|c|c|c|c|}
\hline PROPERTIES & $\begin{array}{c}\text { QUARTZ } \\
{[\underline{11}, \underline{2}, \underline{1}]}\end{array}$ & $\begin{array}{l}\text { LITHIUM } \\
\text { NIOBATE } \\
{[\underline{12}, \underline{6}, \underline{5}, \underline{4}, \underline{3}]}\end{array}$ & $\begin{array}{l}\text { PVDF } \\
{[\underline{13}, \underline{7}]}\end{array}$ & $\begin{array}{c}\text { PZT-NCE55 } \\
{[\underline{9}, \underline{8}]}\end{array}$ & $\begin{array}{c}\text { ROCHELLE } \\
\text { SALT } \\
\text { CRYSTALS } \\
{[10]}\end{array}$ \\
\hline \multicolumn{6}{|l|}{$\begin{array}{c}\text { Piezoelectric charge } \\
\text { constants }\end{array}$} \\
\hline$d_{33}\left(x 10^{-12}\right)$ & 2.00 & 6.00 & $-32.5^{\star}$ & 670.00 & 420.00 \\
\hline \multicolumn{6}{|c|}{ Relative dielectric constant } \\
\hline $\mathrm{K}_{3}^{\top}$ & 4.6 & 28.70 & 7.60 & 5000.00 & 5000.00 \\
\hline \multicolumn{6}{|l|}{$\begin{array}{l}\text { Piezoelectric voltage } \\
\text { constants }\end{array}$} \\
\hline$g_{33}\left(\times 10^{-2}\right)$ & 5.00 & 2.30 & 48.00 & 1.90 & 0.94 \\
\hline \multicolumn{6}{|c|}{$\begin{array}{l}\text { Electromechanical coupling } \\
\text { factor }(\%)\end{array}$} \\
\hline $\mathrm{k}_{33}$ & 28.00 & 25.00 & 19.00 & 72.00 & 90.00 \\
\hline \multicolumn{6}{|l|}{ Elastic compliance } \\
\hline $\mathrm{S}_{33^{E}}\left(\times 10^{-12}\right)$ & 9.56 & 5.03 & 0.05 & 21.00 & 6.30 \\
\hline \multicolumn{6}{|l|}{ Dielectric strength } \\
\hline$X\left(x 10^{6}\right)$ & 8 & 24 & 700 & 100 & 700 \\
\hline
\end{tabular}

* Negative value indicates the presence of a greater number of electrons than protons and positive value indicates the presence of a greater number of protons than electrons.

From the table it can be seen that the highest conversion rate of mechanical energy to electrical is that of Rochelle salt (90) and then followed by PZT-NCE55 (72). The rest of the materials have a much lower conversion rate. 
PVDF can produce the maximum amount of voltage for given dimensions, while for the same dimensions the other materials would produce lower voltages. This is the result of PVDF's high voltage constant $\left(48 \times 10^{-2}\right)$. However, in comparison the other materials have much lower voltage constants.

The relative dielectric constants are similar for PZT-NCE55 and Rochelle salt, but the remaining materials have much lower relative dielectric values. As a result, the Rochelle salt and PZTNCE55 crystals have much higher capacitance than the rest - for given dimensions. Thus, they can produce more energy.

All the selected materials have similar stress holding capacities and are equally suited to use in the product.

\section{Calculations of respective materials}

\begin{tabular}{|c|c|c|c|c|c|}
\hline & QUARTZ & $\begin{array}{c}\text { LITHIUM } \\
\text { NIOBATE }\end{array}$ & PVDF & PZT-NCE55 & $\begin{array}{c}\text { ROCHELLE } \\
\text { SALT } \\
\text { CRYSTALS }\end{array}$ \\
\hline $\begin{array}{c}\text { Number of } \\
\text { crystals per tile }\end{array}$ & 10 & 10 & 10 & 10 & 10 \\
\hline $\begin{array}{c}\text { Area of crystal } \\
\text { (sq m) }\end{array}$ & $5.0 \times 10^{-5}$ & $7.6 \times 10^{-8}$ & $4.1 \times 10^{-8}$ & $11.4 \times 10^{-9}$ & $8 \times 10^{-10}$ \\
\hline $\begin{array}{c}\text { Distance } \\
\text { between } \\
\text { electrodes (m) }\end{array}$ & $1.0 \times 10^{-2}$ & $1.0 \times 10^{-2}$ & $1.0 \times 10^{-2}$ & $1.0 \times 10^{-2}$ & $1.0 \times 10^{-2}$ \\
\hline $\begin{array}{c}\text { VOLTAGE } \\
\text { (volts) }\end{array}$ & $6.0 \times 10^{4}$ & $18.0 \times 10^{4}$ & $7.0 \times 10^{6}$ & $1.0 \times 10^{6}$ & $7.0 \times 10^{6}$ \\
\hline $\begin{array}{c}\text { CAPACITANCE } \\
\text { (farad) }\end{array}$ & $1.6 \times 10^{-7}$ & $2.5 \times 10^{-16}$ & $2.7 \times 10^{-16}$ & $5.0 \times 10^{-14}$ & $4.5 \times 10^{-16}$ \\
\hline $\begin{array}{c}\text { ENERGY PER } \\
\text { STEP (joules) }\end{array}$ & $3.6 \times 10^{-5}$ & $4.0 \times 10^{-5}$ & $6.0 \times 10^{-2}$ & $2.5 \times 10^{-1}$ & $1.0 \times 10^{-1}$ \\
\hline
\end{tabular}

The table shows the area of cross section of one tile to generate the required voltage which also sets the effective capacitance. From the table it is visible that the highest amount of energy produced per step was $2.5 \times 10^{-1}$ by PZT-NCE55. However, this efficiency is not enough to power 4 lights for 5 hours in a classroom. 
In a typical classroom, there are 50 students and to be able generate enough energy from their steps to power 4 tube lights $(60 \mathrm{~W})$ for 5 hours, the product needs to be able to produce 28.8 joules of energy per step - from one tile.

\section{Conclusion}

In Conclusion the experiments and data analysis indicate that the use of current materials is limited in its capabilities, therefore being unable to make the idea of generating energy from footsteps feasible. The idea sure is a vision towards sustainability but the need for more advancement in technology is required to be able to efficiently make this idea a working model. Over time, as extensive research goes into sustainable material development, we will be equipped with the technology to come through with this idea.

\section{References}

1. “8. Relative Permittivity.” チップワンストップ - 電子部品・半導体の通販サイト Sp, 15 Nov. 2018, https://www.chip1stop.com/sp/knowledge/008 Relative-permittivity de.

2. Crystran. "Quartz Crystal (sio2)." Quartz Crystal (SiO2) Optical Material, https://www.crystran.co.uk/optical-materials/quartz-crystal-sio2.

3. Chen, Feifei, et al. "The Electromechanical Features of linbo3 Crystal for Potential High Temperature Piezoelectric Applications." Journal of Materiomics, Elsevier, 11 Oct. 2018, https://www.sciencedirect.com/science/article/pii/S2352847818300923

4. eFunda, Inc. "Home." EFunda, https://www.efunda.com/materials/piezo/material data/matdata output.cfm?Material ID $=\mathrm{LiNbO}$.

5. "Lithium Niobate - Boston Piezo-Optics Inc.." Boston Piezo Optics Inc., https://www.bostonpiezooptics.com/lithium-niobate.

6. "Lithium Niobate Properties." The Roditi International Corporation Ltd, http://www.roditi.com/SingleCrystal/LiNbO3/liNBO3-Properties.html.

7. Diederichs, Rolf. "PVDF and Array Transducers." PVDF and Array Transducers S, https://www.ndt.net/article/rocky/rocky.htm.

8. “NCE 55." Seacorpiezo, 19 Mar. 2020, https://seacorpiezo.com/materialspecifications/lead-zirconate-titanate-soft/nce-55/.

9. Piezo Materials - MMech. https://www.mmech.com/images/stories/Technologies/Piezo\%20Ceramics/Noliac CEra mics NCE datasheet 1404.pdf.

10. "Rochelle Salt." Rochelle Salt - an Overview / ScienceDirect Topics, https://www.sciencedirect.com/topics/engineering/rochelle-salt. 
11. "Table of Dielectric Constants." Ydic.co.jp, http://www.ydic.co.jp/english/technology/table E.html.

12. Rao, R. V. G. Sundara. "THE ELASTIC CONSTANTS OF SODIUM TARTRATE AND ROCHELLE SALT." Https://Www.ias.ac.in/Public/Volumes/Seca/030/04/0173-0180.Pdf, las, 30 Aug. 1949, https://www.ias.ac.in/public/Volumes/seca/030/04/0173-0180.pdf.

13. P AIRMARP Lex TM Piezoelectric Polymer. https://www.airmar.com/images/uploads/AirPDF/Piezoflex.pdf.

14. "Piezoelectric Coefficient." Piezoelectric Coefficient - an Overview / ScienceDirect Topics, https://www.sciencedirect.com/topics/chemistry/piezoelectric-coefficient.

15. Yu, Kuanxin, and Tao Liu. "Calculation of Electromechanical Coupling Coefficient of Quartz Crystal in Decoupling Plane." SPIE Digital Library, SPIE, 17 Nov. 2010, https://www.spiedigitallibrary.org/conference-proceedings-ofspie/7847/78471K/Calculation-of-electromechanical-coupling-coefficient-of-quartzcrystal-in-decoupling/10.1117/12.868351.

16. "Piezoelectric Effect." Piezoelectric Effect - an Overview / ScienceDirect Topics, https://www.sciencedirect.com/topics/engineering/piezoelectric-effect.

17. Piezoelectric Voltage Coefficient." Piezoelectric Voltage Coefficient - an Overview / ScienceDirect Topics, https://www.sciencedirect.com/topics/engineering/piezoelectricvoltage-coefficient.

18. Footstep Voltage Generator Using Piezo-Electric Transducers. https://www.ijser.org/researchpaper/Footstep-Voltage-Generator-using-Piezo-ElectricTransducers.pdf.

19. "Piezoelectric Voltage Coefficient." Piezoelectric Voltage Coefficient - an Overview / ScienceDirect Topics, https://www.sciencedirect.com/topics/engineering/piezoelectricvoltage-coefficient.

20. "Piezoelectric Voltage." Piezoelectric Voltage - an Overview / ScienceDirect Topics, https://www.sciencedirect.com/topics/engineering/piezoelectric-voltage.

21. Song, Jundong, et al. "Design Optimization of PVDF-Based Piezoelectric Energy Harvesters." Heliyon, Elsevier, 12 Sept. 2017, https://www.sciencedirect.com/science/article/pii/S240584401731263X.

22. Xie, Mengying, et al. "Flexible and Active Self-Powered Pressure, Shear Sensors Based on Freeze Casting Ceramic-Polymer Composites." Energy \& Environmental Science, Royal Society of Chemistry, 1 Oct. 2018, https://www.ncbi.nlm.nih.gov/pmc/articles/PMC6333270/. 